\title{
An Approach to the Model use for Measuring Suspended Sediment Yield in Ungauged Catchments
}

\author{
Sokchhay Heng and Tadashi Suetsugi \\ Interdisciplinary Graduate School of Medicine and Engineering, \\ University of Yamanashi, 4-3-11 Takeda, Kofu, Yamanashi 400-8511, Japan
}

Received 2013-07-12; Revised 2013-09-03; Accepted 2013-09-11

\begin{abstract}
Different types of water resources studies require the information of Suspended Sediment Yield (SSY) in different time resolutions. In ungauged watersheds where hydrometeorogical time series are not available, the mean annual SSY (SSY $)$ is solely predictable and catchment area is traditionally used as the predictor because it is the most important variable and generally determined during project planning. Firstly, this research tried to advance the traditional $\mathrm{SSY}_{\mathrm{a}}$ model by additionally associating global topographic data. Based on the jack-knife procedure, the modified method considering catchment area with slope greater than $15 \%$ was evaluated in 17 gauged catchments in the Lower Mekong Basin and the overall predictive accuracy was improved about $66 \%$ in term of mean absolute percentage error. Secondly, the predicted SSY in each modeled catchment was monthly distributed using Unit mean annual Sedimentograph (USG $)_{\mathrm{a}}$ ). The double-average $\mathrm{USG}_{\mathrm{a}}$ superior to the single-average one provides overall better quality results than the regionalized $\mathrm{USG}_{\mathrm{a}}$ dependent upon the spatial proximity approach. The model performance measured by Nash-Sutcliffe Efficiency (NSE) is about 0.66 in median value and satisfactory results (NSE $>0.50)$ are obtained in 11 catchments. Lastly, the validated regional model was regarded as a potential and feasible tool in solving sediment-ungauged issues in the basin.
\end{abstract}

Keywords: Sediment Yield, Ungauged Catchment, Unit Sedimentograph, Spatial Proximity, Mekong Basin

\section{INTRODUCTION}

Sediment yield is the amount of sediment discharged by a catchment over a period of time. In alluvial rivers, it often depends on suspended load which is the predominant portion and commonly accounts for more or less 90\% (Walling and Fang, 2003; Francke et al., 2008; Zhang et al., 2012). Quantification of Suspended Sediment Yield (SSY) in rivers is crucial for issues of soil erosion, water quality, reservoir sedimentation, fish habitat and other ecological impacts (Morris and Fan, 1998; Melesse et al., 2011; Isik, 2013). Unfortunately, sediment-observed data are lacking for rivers in many parts of the world, especially in developing and remote regions (Walling and Fang, 2003). Although some gauged rivers are existent, the sampling frequency is commonly low (monthly or larger time scale). To deal with this problem, numerous modeling tools have been developed and empirical approach is the most popular in data-constraint areas because it does not require detailed watershed physical information. Land use, geology, hydrometeorology and other factors physically affect land surface erosion and sediment transport but it is usually difficult to collect proper and accurate data for all watersheds (Isik, 2013).

The simplest and most widely used empirical model is sediment rating curve, the average relationship between discharge and sediment (Wang et al., 2007; Zhang et al., 2012; Isik, 2013). This method can be applied to predict SSY time series with the known discharge information. On the other hand, there are also limited streamflow monitoring stations worldwide. This

Corresponding Author: Sokchhay Heng, Interdisciplinary Graduate School of Medicine and Engineering,

University of Yamanashi, 4-3-11 Takeda, Kofu, Yamanashi 400-8511, Japan 
could be evidential from many recently published researches related to rainfall-runoff modeling in ungauged basins, i.e., Bao et al. (2012); Zhao et al. (2012); Cibin et al. (2013) and Seibert and McDonnell (2013). In this regard, another empirical approach associating catchment Area $\left(\mathrm{A}_{0}\right)$ as a predictor is often in use. Although this technique enables solely the point value prediction such as mean annual SSY $\left(\mathrm{SSY}_{\mathrm{a}}\right)$, it is surely feasible because $A_{0}$, the most important variable, is generally determined during project planning (Tamene et al., 2006). Applications of the $\mathrm{A}_{0}-\mathrm{SSY}_{\mathrm{a}}$ relationship can be found in various existing studies, e.g., Verstraeten et al. (2002); Tamene et al. (2006) and Kummu et al. (2010).

Some developments of water resources system require the information of SSY in monthly or sometimes daily basis. Therefore, in ungauged basins, it is necessary to distribute the predicted $\mathrm{SSY}_{\mathrm{a}}$ (from modeling tools) into smaller time scale. One possible technique is the use of Unit mean annual Sedimentograph $\left(\mathrm{USG}_{\mathrm{a}}\right)$. In this research, ordinates of $\mathrm{USG}_{\mathrm{a}}$ were designed as $\mathrm{SSY}_{\mathrm{m}} / \mathrm{SSY}_{\mathrm{a}}$ where $\mathrm{SSY}_{\mathrm{m}}$ is the mean monthly SSY and this allows backward computation of $\mathrm{SSY}_{\mathrm{m}}$ when $\mathrm{SSY}_{\mathrm{a}}$ is known. In gauged basins, the $\mathrm{USG}_{\mathrm{a}}$ model can be calibrated using the observed records. To our knowledge, this is the first experimental study and therefore, related literatures are impossibly given. Methodology of the proposed $\mathrm{USG}_{\mathrm{a}}$ model was given in next section.

A large number of hydropower projects have been planned in the Lower Mekong Basin (LMB) and majority of them is located in the basin part of Lao PDR, Cambodia and Vietnam (MRC, 2011). However, sediment data are poorly gauged or mostly ungauged at desired sites where hydropower plants are to be developed. SSY plays an important role in sustaining such developments (Isik, 2013). For instance, it is required for design of reservoir life and storage capacity (Morris and Fan, 1998). In this basin, there are in total 60 sediment monitoring stations and most of them are situated in the basin part of Thailand. Therefore, establishment of a regional model, based on gauged catchments, for use in ungauged sites is very important in this basin.

The main objective of this study is to develop a feasible regional model for predicting SSY in ungauged catchments in the LMB. First, we established an empirical approach functionable with the easily and globally available data, catchment area and topography, for $\mathrm{SSY}_{\mathrm{a}}$ prediction. Second, we validated the proposed $\mathrm{USG}_{\mathrm{a}}$ model in monthly distributing the predicted $\mathrm{SSY}_{\mathrm{a}}$. Ungauged catchment here refers to one having no hydrometeorogical data such as sediment, discharge, rainfall and so forth.

\section{MATERIALS AND METHODS}

\subsection{Study Area and Datasets}

The study area is focused on the LMB covering part of Lao PDR, Thailand, Cambodia and Vietnam. It lies between latitudes 8 to $23^{\circ} \mathrm{N}$ and longitudes 98 and $109^{\circ}$ E. The basin elevation varies from just over $2800 \mathrm{~m}$ in the highland area of Lao PDR to about zero at the coast in the delta in Vietnam (Fig. 1). It is influenced by two main seasons, rainy season (May-October) and dry season (November-April). The mean annual rainfall over the basin is greatly variable, ranging from less than 1000 to more than $2500 \mathrm{~mm}$. This basin behaves a wide diversity of drainage patterns including simple dentritic tributary networks that resemble a branching tree, very straight rivers and a variety of irregular patterns characterized by streams with abrupt changes in course. Land use in this study area can be broadly divided into three main components: paddy, forested land and land cultivated for field crops. Paddy (about $24 \%$ of the basin area) dominates the vast low-lying alluvial plains of the basin. The large majority of the basin part of Lao PDR and Cambodia is covered by forest, a mix of evergreen and deciduous types. Field crops are extensively found within the gently sloping upland areas in Thailand. Acrisols are the most common soil type in the LMB overall and cover about $60 \%$ of the total drainage area.

Among 46 sediment gauging stations in the tributary rivers, only 18 (2 in Lao PDR and 16 in Thailand) are possibly selected for the study because others contain only few years of records with very low sampling frequency (less than one sample per month). Drainage catchment of each station was delineated using Digital Elevation Model (DEM) of 30-m resolution, downloaded from ASTER GDEM Version 2. ASTER GDEM is a product of METI and NASA. DEM was also applied for slope computation. Daily data of discharge (Q) and Suspended Sediment Concentration (SSC) were obtained from Mekong River Commission. There are no damreservoirs operated during which the considered datasets were observed (MRC, 2009). The SSC sampling method and data reliability discussion can be found in Wang et al. (2009) and Walling (2005), respectively. SSY data are derived from the product of Q and SSC. Because SSC time series contain only few samples per month, all computations in this study are monthly base. Data information and catchment characteristics are summarized in Table 1. It should be noted that $A_{5}, A_{10}$, $\mathrm{A}_{15}, \mathrm{~A}_{20}$ and $\mathrm{A}_{30}$ represent catchment areas with slopes greater than $5,10,15,20$ and $30 \%$, respectively. 
Sokchhay Heng and Tadashi Suetsugi / American Journal of Environmental Science 9 (4): 367-376, 2013

Table 1. Data information and catchment characteristics

\begin{tabular}{|c|c|c|c|c|c|c|c|c|c|c|c|}
\hline CAT & $\begin{array}{l}\text { Length* } \\
\text { (year) }\end{array}$ & $\begin{array}{l}\mathrm{A}_{0} \\
\left(\mathrm{~km}^{2}\right)\end{array}$ & $\begin{array}{l}\mathrm{A}_{5} \\
\left(\mathrm{~km}^{2}\right)\end{array}$ & $\begin{array}{l}\mathrm{A}_{10} \\
\left(\mathrm{~km}^{2}\right)\end{array}$ & $\begin{array}{l}\mathrm{A}_{15} \\
\left(\mathrm{~km}^{2}\right)\end{array}$ & $\begin{array}{l}\mathrm{A}_{20} \\
\left(\mathrm{~km}^{2}\right)\end{array}$ & $\begin{array}{l}\mathrm{A}_{30} \\
\left(\mathrm{~km}^{2}\right)\end{array}$ & $\begin{array}{l}\mathrm{S}_{\mathrm{c}} \\
(\%)\end{array}$ & $\begin{array}{l}\mathrm{S}_{\mathrm{r}} \\
(\%)\end{array}$ & $\begin{array}{l}\mathrm{Q}_{\mathrm{a}} \\
\left(\mathrm{m}^{3} / \mathrm{s}\right)\end{array}$ & $\begin{array}{l}\mathrm{SSY}_{\mathrm{a}} \\
\text { (M ton/year) }\end{array}$ \\
\hline 1 & 25 & 3171 & 2296 & 1095 & 469 & 225 & 70 & 9 & 8 & 37.21 & 0.116 \\
\hline 2 & 20 & 1405 & 1280 & 1020 & 770 & 584 & 350 & 22 & 15 & 17.10 & 0.062 \\
\hline 3 & 20 & 3249 & 3062 & 2690 & 2308 & 1957 & 1273 & 27 & 10 & 23.97 & 0.152 \\
\hline 4 & 22 & 260 & 256 & 244 & 224 & 198 & 136 & 32 & 16 & 2.22 & 0.015 \\
\hline 5 & 16 & 1412 & 1203 & 819 & 505 & 318 & 136 & 15 & 16 & 23.81 & 0.060 \\
\hline 6 & 14 & 1220 & 1071 & 789 & 543 & 376 & 172 & 17 & 10 & 18.67 & 0.116 \\
\hline 7 & 20 & 1886 & 1738 & 1452 & 1185 & 975 & 638 & 26 & 12 & 25.99 & 0.103 \\
\hline 8 & 19 & 522 & 513 & 488 & 447 & 393 & 263 & 32 & 16 & 11.33 & 0.107 \\
\hline 9 & 13 & 6182 & 5903 & 5308 & 4636 & 3974 & 2654 & 29 & 26 & 105.00 & 0.760 \\
\hline 10 & 34 & 3414 & 3326 & 3102 & 2782 & 2412 & 1602 & 31 & 27 & 68.22 & 0.453 \\
\hline 11 & 22 & 428 & 421 & 403 & 372 & 333 & 235 & 34 & 17 & 5.51 & 0.044 \\
\hline 12 & 32 & 1256 & 1128 & 877 & 648 & 483 & 266 & 20 & 15 & 18.38 & 0.135 \\
\hline 13 & 34 & 795 & 696 & 510 & 331 & 209 & 83 & 16 & 14 & 9.09 & 0.055 \\
\hline 14 & 27 & 10,806 & 8367 & 4725 & 2568 & 1582 & 765 & 12 & 10 & 57.90 & 0.173 \\
\hline 15 & 22 & 233 & 226 & 207 & 179 & 150 & 96 & 29 & 16 & 10.66 & 0.022 \\
\hline 16 & 21 & 2385 & 1919 & 1210 & 667 & 369 & 123 & 12 & 11 & 37.32 & 0.103 \\
\hline 17 & 7 & 19,704 & 19,430 & 18,679 & 17,492 & 15,989 & 12,201 & 38 & 45 & 546.40 & 4.442 \\
\hline 18 & 7 & 6482 & 6405 & 6182 & 5817 & 5344 & 4137 & 39 & 41 & 117.77 & 0.841 \\
\hline
\end{tabular}

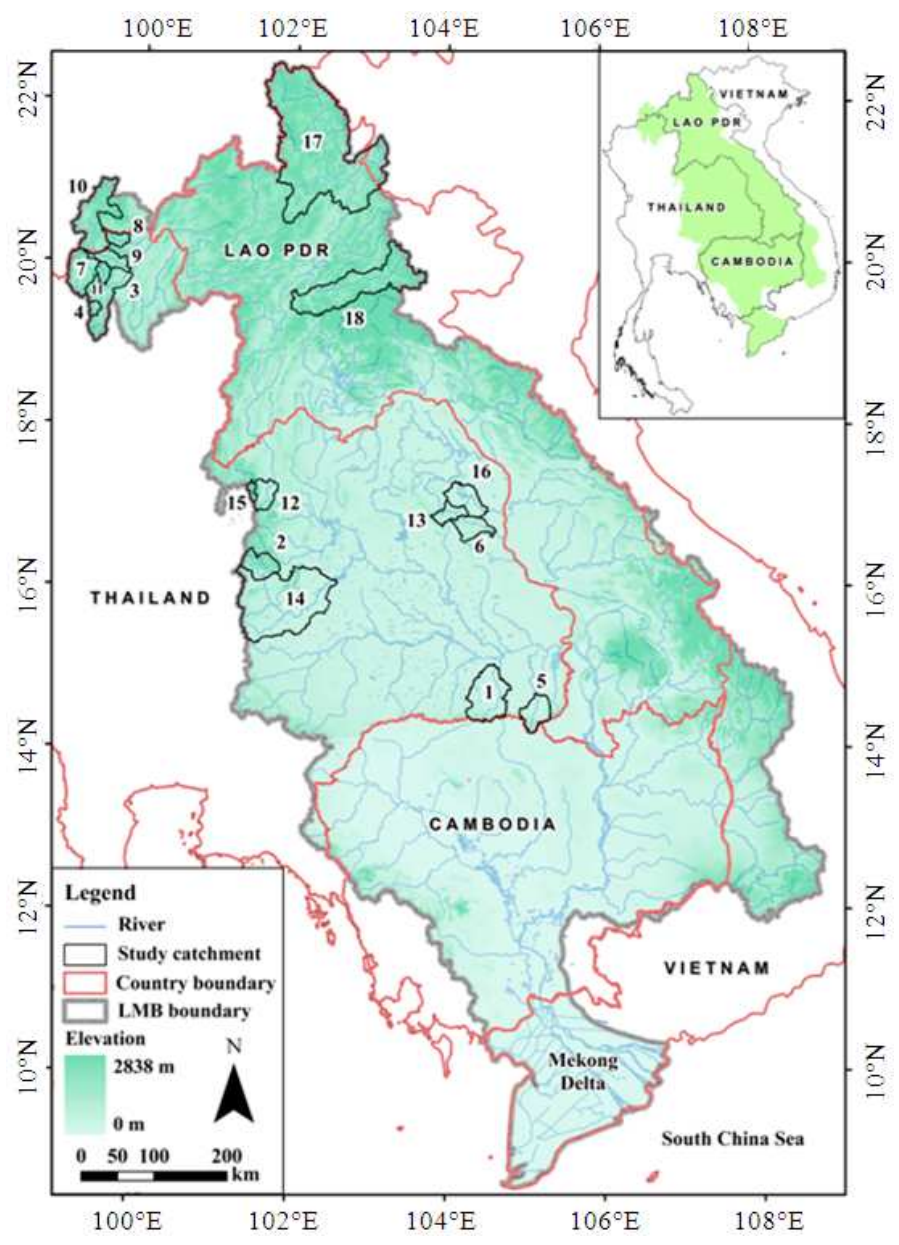

Fig. 1. Location map of the study catchments 


\subsection{Mean Annual Suspended Sediment Yield $\left(\right.$ SSY $\left._{\mathrm{a}}\right)$ Model}

$\mathrm{SSY}_{\mathrm{a}}$ is traditionally predicted using empirical relationships (linear or non-linear) developed on gauged areas and the most common predictor is catchment Area $\left(\mathrm{A}_{0}\right)$. Topography is also an important factor involved in sediment prediction using simple empirical models (Verstraeten et al., 2002). Since global DEM is currently available for free of charge, $\mathrm{A}_{5}, \mathrm{~A}_{10}, \mathrm{~A}_{15}, \mathrm{~A}_{20}$ and $\mathrm{A}_{30}$ were also tried alternately instead of $A_{0}$ itself. All relationships were checked for correlation strength and statistical significance test (t-test). The qualified relationships should have $\mathrm{R}^{2} \geq 0.49$, $\mathrm{t}_{\text {statistic }}>\mathrm{t}_{\alpha=0.05}$ and $\mathrm{p}$ value $<0.01$ (Heng and Suetsugi, 2013).

The jack-knife procedure was applied for evaluation purpose. The concept of this procedure is that each of the gauged catchments is in turn regarded as ungauged, termed pseudo ungauged catchment. For site-specific error measure, Percentage Error (PE) was used while Mean Absolute Percentage Error (MAPE) was employed to assess the overall predictive accuracy of each alternative $\operatorname{SSY}_{\mathrm{a}}$ model Equation (1 and 2):

$$
\begin{aligned}
& \mathrm{PE}=100 \times \frac{\mathrm{P}_{\mathrm{i}}-\mathrm{O}_{\mathrm{i}}}{\mathrm{O}_{\mathrm{i}}} \\
& \mathrm{MAPE}=100 \times \frac{1}{\mathrm{n}} \sum_{\mathrm{i}=1}^{\mathrm{n}} \frac{\left|\mathrm{P}_{\mathrm{i}}-\mathrm{O}_{\mathrm{i}}\right|}{\mathrm{O}_{\mathrm{i}}}
\end{aligned}
$$

where, $\mathrm{P}_{\mathrm{i}}$ and $\mathrm{O}_{\mathrm{i}}$ is respectively the predicted and observed SSY $_{a}$ in catchment $i$ and $n$ is the number of catchments. The $\mathrm{R}^{2}$ and MAPE values of all proposed relationships were optimized. The one having optimum $\mathrm{R}^{2}$ and MAPE

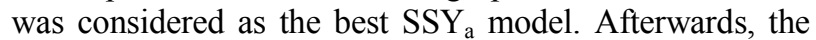
predicted $\mathrm{SSY}_{\mathrm{a}}$ from the best model were distributed monthly over a period of one year using $\mathrm{USG}_{\mathrm{a}}$.

\subsection{Unit Mean Annual Sedimentograph (USG ${ }_{a}$ )}

Representative mean annual sedimentograph (SSY vs time) of each catchment was obtained by averaging SSY in each specific month. Its ordinates were then divided by $\mathrm{SSY}_{\mathrm{a}}$ (or area under the graph) to generate Unit mean annual Sedimentograph $\left(\mathrm{USG}_{\mathrm{a}}\right)$. The word "unit" denotes unity of area under $\mathrm{USG}_{\mathrm{a}}$. In this research, $\mathrm{USG}_{\mathrm{a}}$ was considered as a simple linear model which can be used to monthly distribute $\mathrm{SSY}_{\mathrm{a}}$ Equation (3):

$$
\operatorname{SSY}_{\mathrm{m}, \mathrm{j}}=\operatorname{SSY}_{\mathrm{a}} \times \mathrm{U}_{\mathrm{j}}
$$

where, $\mathrm{SSY}_{\mathrm{m}, \mathrm{j}}$ and $\mathrm{U}_{\mathrm{j}}$ is respectively the $\mathrm{SSY}_{\mathrm{m}}$ and ordinate of $\mathrm{USG}_{\mathrm{a}}$ for month $\mathrm{j}$. In this study, we compared two alternatives of the $\mathrm{USG}_{\mathrm{a}}$ model. First is the use of average $\mathrm{USG}_{\mathrm{a}}$ in which each ordinate $\left(\mathrm{SSY}_{\mathrm{m}} / \mathrm{SSY}_{\mathrm{a}}\right)$ was calculated as the mean of those from all gauged catchments and the jack-knife procedure was applied as well in this case. In the second alternative, $\mathrm{USG}_{\mathrm{a}}$ of the target ungauged catchment was transposed from a donor catchment using the spatial proximity regionalization approach. The hypothesis of this approach is that catchments geographically close to each other should have similar characteristics (Zhang and Chiew, 2009) and in this study corresponding to similar $\mathrm{USG}_{\mathrm{a}}$ model. Spatial proximity is advantageous for its using the full information content of the locally calibrated models. Furthermore, it favors data-constraint regions because it does not require detailed information of the catchment attributes. The Distance (D) between catchment centroids was regarded as the distance measure (Zhao et al., 2012). For example, for validation in CAT1 , the donor catchment is CAT-5 which is the most nearest one $(\mathrm{D}=70 \mathrm{~km})$. Hence, the calibrated $\mathrm{USG}_{\mathrm{a}}$ in CAT-5 was selected to compute SSY $\mathrm{m}_{\mathrm{m}}$ in CAT-1.

In each modeled catchment, the predicted mean annual sedimentograph was compared with the observed one so as to determine the model performance statistically measured by Nash-Sutcliffe Efficiency (NSE). For sediment modeling in monthly basis, the predictive accuracy is judged as satisfactory in case NSE is greater than 0.50 while negative NSE indicates that the observed mean value is a better predictor than the model being used Equation (4) (Moriasi et al., 2007):

$$
\mathrm{NSE}=1-\frac{\sum_{\mathrm{j}=1}^{12}\left(\mathrm{O}_{\mathrm{j}}-\mathrm{P}_{\mathrm{j}}\right)^{2}}{\sum_{\mathrm{j}=1}^{12}\left(\mathrm{O}_{\mathrm{j}}-\mathrm{O}_{\mathrm{avg}}\right)^{2}}
$$

where, $\mathrm{O}_{\mathrm{j}}$ and $\mathrm{P}_{\mathrm{j}}$ is respectively the observed and predicted $\mathrm{SSY}_{\mathrm{m}}$ for month $\mathrm{j}$ and $\mathrm{O}_{\mathrm{avg}}$ is the average observed $\mathrm{SSY}_{\mathrm{m}}$.

\section{RESULTS AND DISCUSSION}

An analysis of the available data showed that about $92 \%$ of SSY are transported during rainy season, from May to October (Fig. 2). The remaining 8\% are transported during dry season, from November to April. In this season, the amount of SSY in November is predominant and accounts for about $4.3 \%$. This could be explained by clockwise hysteretic effect (lag time between Q and SSY) meaning that the eroded materials in October re-deposit and they are then transported by the successive events in November (the extension of rainy season in some years). 


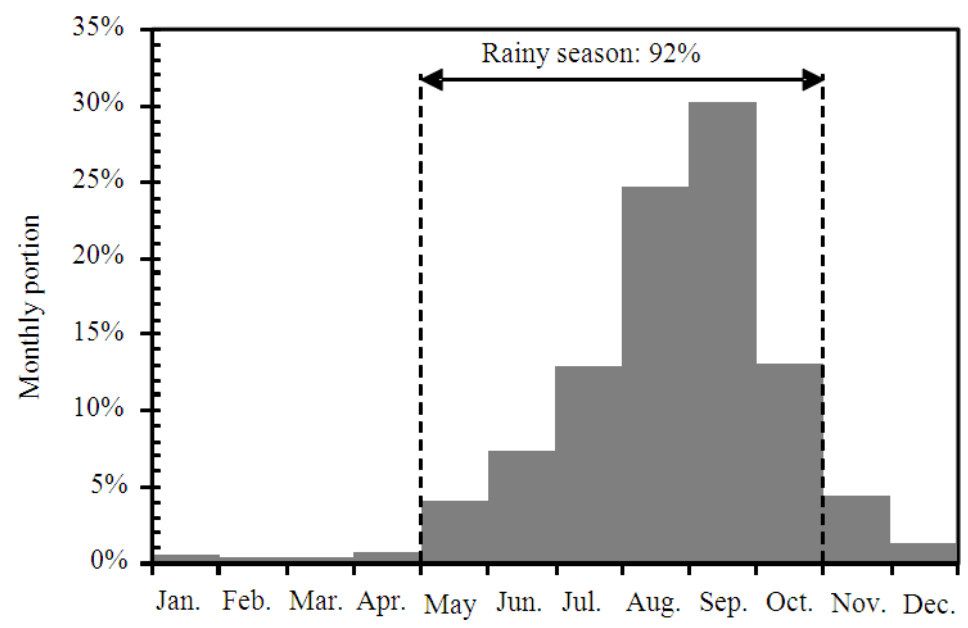

Fig. 2. Monthly distribution of SSY

More or less $83 \%$ of the peak $\mathrm{SSY}_{\mathrm{m}}$ events occur in September while the remaining $17 \%$ do in August and October. In dry season, around $50 \%$ of the minimum $\mathrm{SSY}_{\mathrm{m}}$ events fall in February, 33\% in March and the remaining $17 \%$ in January. The temporal variation of sediment transport could be explained by climate variation and local extreme phenomena such as flood, slope failure.

\subsection{Prediction of SSY}

Excluding Catchment No. 17 (CAT-17), CAT-14 has the maximum $\mathrm{A}_{0}$ and $\mathrm{A}_{5}$ but its corresponding $\mathrm{SSY}_{\mathrm{a}}$ is less than that of CAT-9, CAT-10 and CAT-18. This could be explained further by the topographic feature of each catchment. Steeper catchments generally expose to higher intensity of soil erosion. Overall, CAT-14 contains $\mathrm{A}_{10}$, $\mathrm{A}_{15}, \mathrm{~A}_{20}$ and $\mathrm{A}_{30}$ values less than those of CAT-9, CAT-10 and CAT-18. Together with the evidence of low $\mathrm{R}^{2}$ value, there is no significant relationship between $\mathrm{SSY}_{\mathrm{a}}$ and the size of drainage Area $\left(\mathrm{A}_{0}\right)$ alone.

CAT-17 behaves not only the largest $\mathrm{A}_{0}$ but also $\mathrm{A}_{5}$, $\mathrm{A}_{10}, \mathrm{~A}_{15}, \mathrm{~A}_{20}$ and $\mathrm{A}_{30}$. It contains the largest $\mathrm{SSY}_{\mathrm{a}}$ of 4.442 $\mathrm{M}$ ton/year with the corresponding highest mean annual discharge $\left(Q_{a}\right)$ of $546.40 \mathrm{~m}^{3} / \mathrm{s}$. This catchment is characterized by steep river channel (river channel slope gradient $\left(\mathrm{S}_{\mathrm{r}}\right)=45 \%$ ) producing high unit stream power with the potential for riverbed erosion and sediment transport. It also behaves steep drainage terrain (catchment slope gradient $\left(\mathrm{S}_{\mathrm{c}}\right)=38 \%$ ) corresponding to high erosive factor with the potential for land surface erosion. By visualizing the scatter plots of A-SSY, CAT-17 scatters far away from others and thus not accounted for in the regression analysis to avoid high uncertainty in predicting $\mathrm{SSY}_{\mathrm{a}}$.

Table 2 presents the statistical characteristics of each $\mathrm{A}-S S Y_{\mathrm{a}}$ relationship. The entire relationships pass the statistical test and this reveals the use of adequate sample size for regression fitting. Only $\mathrm{A}_{0}$ exhibits poor correlation with SSY $\left(\mathrm{R}^{2}<0.49\right)$. This clearly demonstrates that the traditional method associating $\mathrm{A}_{0}$ as the predictor is very uncertain. As shown in Fig. 3, $\mathrm{R}^{2}$ value increases continuously from $A_{0}$ to $A_{15}$ and it is rather constant from $A_{15}$ to $A_{30}$. In case of MAPE, it significantly decreases from $\mathrm{A}_{0}$ to $\mathrm{A}_{10}$. After minimizing at $\mathrm{A}_{15}$, moderate increase trend is observed. In other words, the optimum value of MAPE was found with $A_{15}$. This result is in agreement with that of Heng and Suetsugi (2013) and could strongly justify the statement of Fuchs (2004). It should be remarked that the existing study of Heng and Suetsugi (2013) is focused on estimating quantiles of annual maximum SSY. In conclusion, $\mathrm{A}_{15}$ was judged as the best predictor and selected to build the empirical relationship for predicting $\mathrm{SSY}_{\mathrm{a}}$ in ungauged catchments. The $\mathrm{A}_{15}-\mathrm{SSY}_{\mathrm{a}}$ relationship $\left(\mathrm{R}^{2}=0.9038\right)$ was determined as Equation (5):

$$
\operatorname{SSY}_{\mathrm{a}}=0.0001 \mathrm{~A}_{15}-0.0097
$$

By applying the $\mathrm{A}_{15}-\mathrm{SSY}_{\mathrm{a}}$ linear model based on the jack-knife procedure, the predictive accuracy in each modeled catchment is tabulated in Table 3. In term of $\mathrm{PE}, \mathrm{SSY}_{\mathrm{a}}$ in ungauged catchments could be predicted with accuracy between $-55 \%$ and $118 \%$ with an average absolute value (MAPE) of about 44\%. Catchment heterogeneity could explain the difference in predictive accuracy spatially. Negative and positive PE value denotes the under- and over-estimate, respectively. Under-estimates are common for extreme high values. Significant large errors (PE $>100 \%$ ) in CAT-3 and CAT14 are due to large variance of both catchments existent in the regression (Fig. 4). 


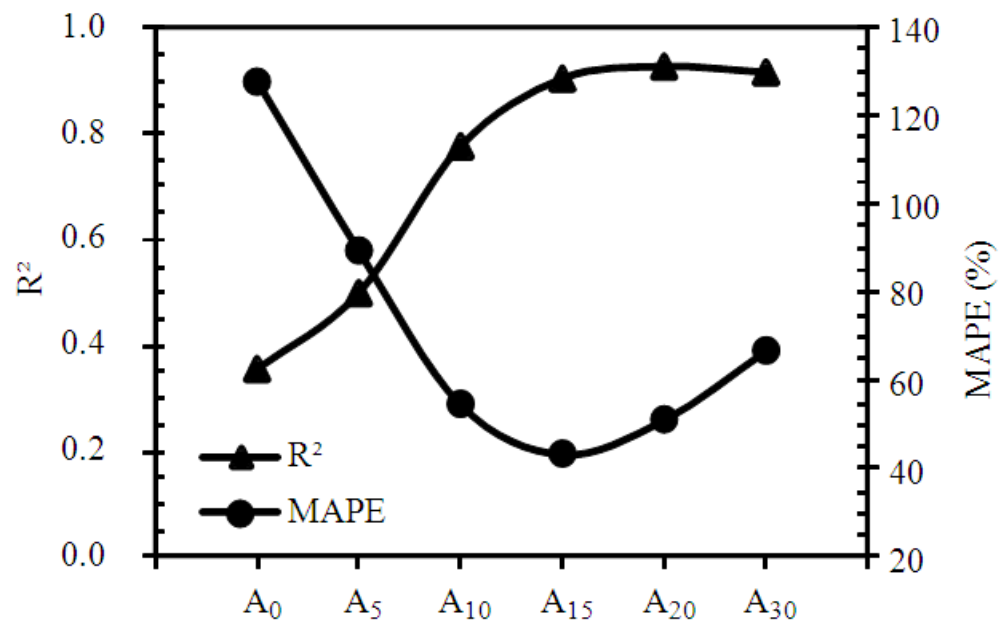

Fig. 3. Optimization of the proposed $\mathrm{SSY}_{\mathrm{a}}$ models

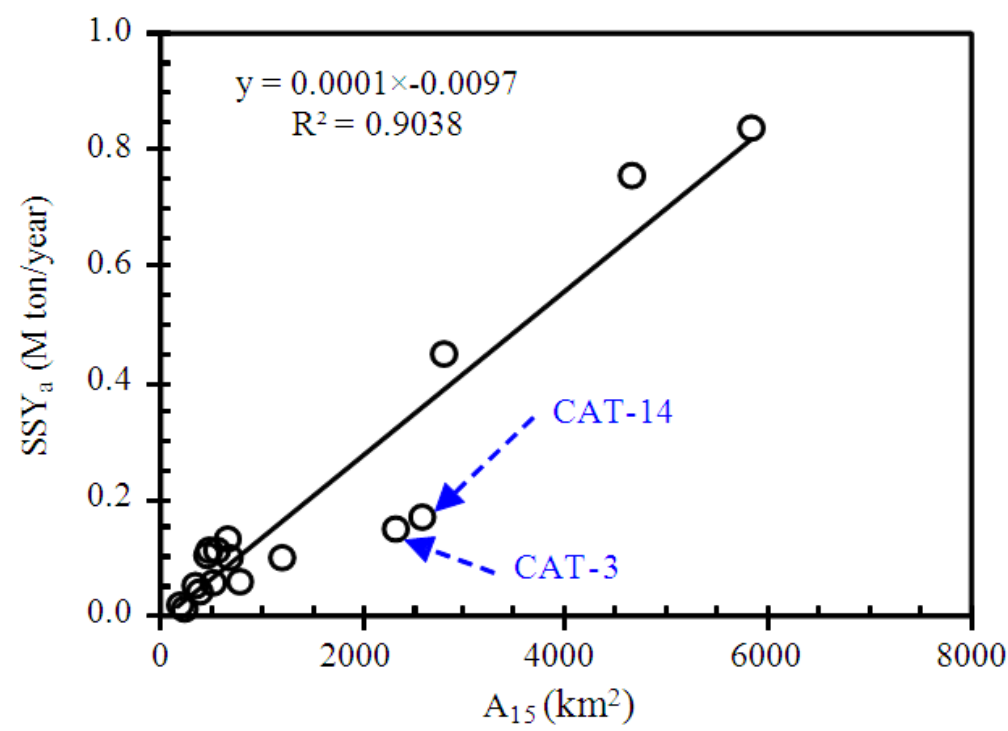

Fig. 4. Graphical illustration of the $\mathrm{A}_{15}-\mathrm{SSY}_{\mathrm{a}}$ relationship

Table 2. Statistical characteristics of the A-SSY linear

\begin{tabular}{llrrl}
\multicolumn{5}{c}{ relationships } \\
\hline Predictor & $\mathrm{R}^{2}$ & $\mathrm{t}_{\text {statistic }}$ & $\mathrm{p}$-value & MAPE (\%) \\
\hline $\mathrm{A}_{0}$ & 0.36 & 2.875 & 0.0090 & 128 \\
$\mathrm{~A}_{5}$ & 0.50 & 3.864 & 0.0011 & 90 \\
$\mathrm{~A}_{10}$ & 0.78 & 7.215 & $<0.0001$ & 55 \\
$\mathrm{~A}_{15}$ & 0.90 & 11.873 & $<0.0001$ & 44 \\
$\mathrm{~A}_{20}$ & 0.93 & 13.736 & $<0.0001$ & 51 \\
$\mathrm{~A}_{30}$ & 0.92 & 12.744 & $<0.0001$ & 67 \\
\hline
\end{tabular}

\subsection{Distribution of $\operatorname{SSY}_{\mathrm{a}}$ Using Average $\mathrm{USG}_{\mathrm{a}}$}

It should be noted that CAT-17 was also excluded in this section. The predicted $\mathrm{SSY}_{\mathrm{a}}$ in each modeled catchment was distributed monthly based upon the average USG $_{a}$ graphically illustrated in Fig. 5. Using the jack-knife procedure, the predictive accuracy in term of NSE varies from -2.38 to 0.97 (median $=0.61$ ). There are in total 10 satisfactorily modeled catchments (NSE > 0.50 ). Similarly, significant low accurate results occur in CAT-3 and CAT-14. This could be explained by large errors containing in the predicted $\mathrm{SSY}_{\mathrm{a}}$.

Using only the single model of average $\mathrm{USG}_{\mathrm{a}}$ might not represent well diversity of catchment characteristics. In Fig. 5, it is evident that there is a 
remarkable gap between two groups of site-specific $\mathrm{USG}_{\mathrm{a}}$ : Under and above the peak of 0.306 . It also means that the single-average $\mathrm{USG}_{\mathrm{a}}$ is distorted because there is no any peak in the group having that value $(0.306)$ or close proximity. In order to advance the predictive accuracy, various catchment attributes were used alternately as constraint variable to classify the site-specific $\mathrm{USG}_{\mathrm{a}}$ and $\mathrm{A}_{0}$ was found as the best one. In this classification, there are nine and eight $\mathrm{USG}_{\mathrm{a}}$ located under and above $\mathrm{A}_{0}$ of around 1650 $\mathrm{km}^{2}$, respectively. Average $\mathrm{USG}_{\mathrm{a}}$ was then computed for each group as depicted in Fig. 5. It can be seen that the double-average $\mathrm{USG}_{\mathrm{a}}$ represents better the entire candidate $\mathrm{USG}_{\mathrm{a}}$.

By employing the double-average $\mathrm{USG}_{\mathrm{a}}$ model, the predictive accuracy in each modeled catchment is presented in Table 3. NSE ranges from -1.94 to 0.96 with a median value of 0.66 . There are 11 satisfactorily modeled catchments in this case. In comparing with the results yielded from the single-average $\mathrm{USG}_{\mathrm{a}}$, the uncertainty (range of NSE) was reduced together with larger median NSE about $8 \%$. Number of satisfactorily modeled catchments also increases. To sum up, the doubleaverage $\mathrm{USG}_{\mathrm{a}}$ is superior to the single-average one.

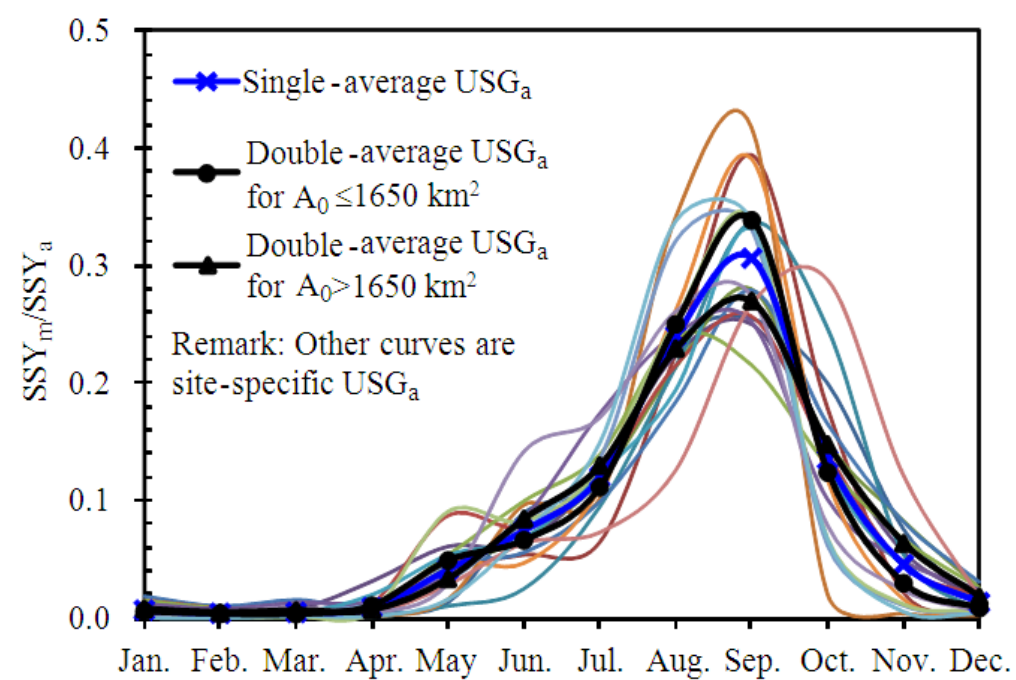

Fig. 5. Unit mean annual sedimentograph $\left(\mathrm{USG}_{\mathrm{a}}\right)$

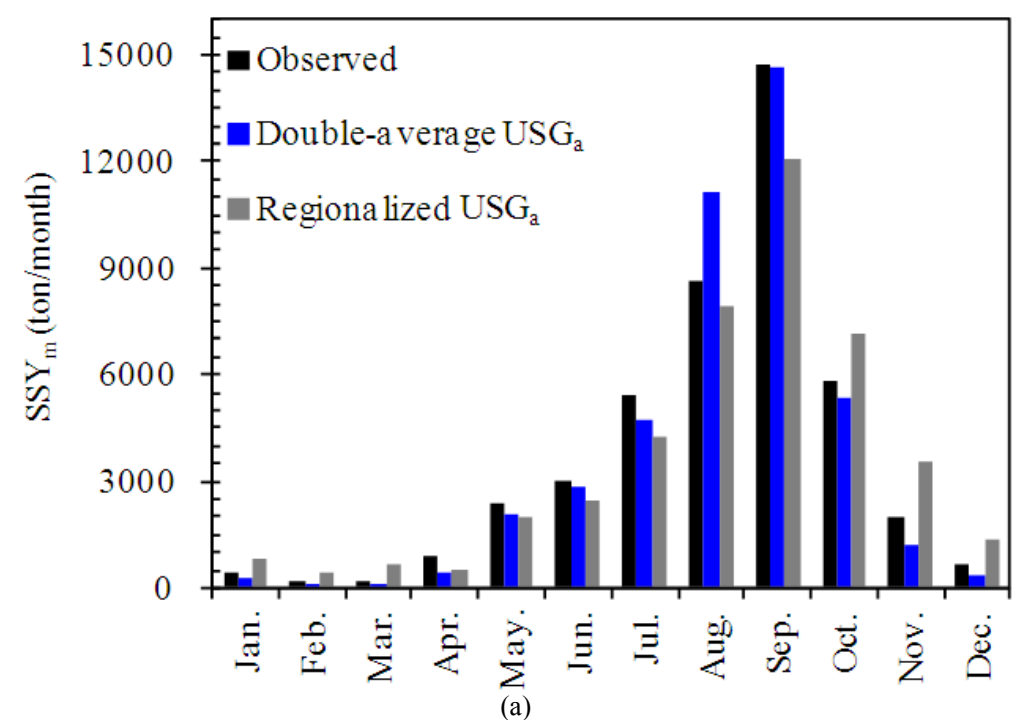




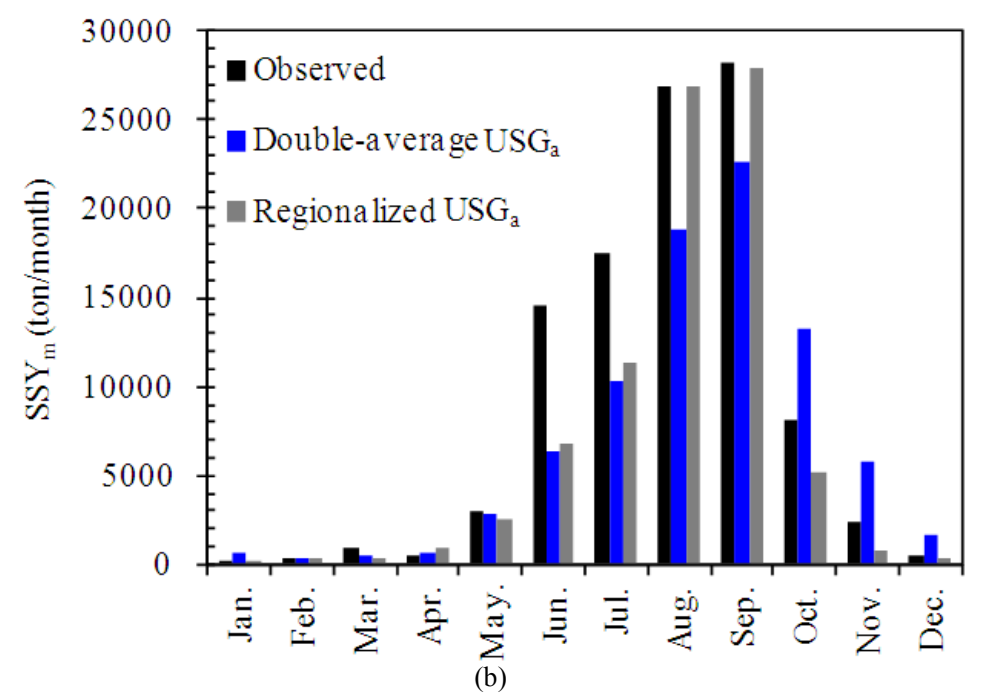

Fig. 6. Comparison between the predicted and observed SSY $\mathrm{m}_{\mathrm{m}}$ in (a) CAT-11 and (b) CAT-16

Table 3. Site-specific model performance

\begin{tabular}{|c|c|c|c|c|c|}
\hline \multirow[b]{2}{*}{ CAT } & \multirow[b]{2}{*}{$\begin{array}{l}\mathrm{PE}(\%) \\
\left(\mathrm{SSY}_{\mathrm{a}} \text { model }\right)\end{array}$} & \multicolumn{4}{|c|}{ NSE (SSY ${ }_{m}$ model) } \\
\hline & & $\begin{array}{l}\text { Single-average } \\
\mathrm{USG}_{\mathrm{a}}\end{array}$ & $\begin{array}{l}\text { Double-average } \\
\text { USG }_{a}\end{array}$ & $\begin{array}{l}\text { Regionalized } \\
\text { USG }_{a}\end{array}$ & $\begin{array}{l}\text { Donor } \\
\text { catchment* }\end{array}$ \\
\hline 1 & -55 & 0.43 & 0.40 & 0.50 & 5 \\
\hline 2 & 66 & 0.55 & 0.47 & 0.19 & 14 \\
\hline 3 & 118 & -2.38 & -1.82 & -1.42 & 4 \\
\hline 4 & 52 & -0.01 & -0.41 & 0.26 & 3 \\
\hline 5 & 4 & 0.87 & 0.82 & 0.91 & 1 \\
\hline 6 & -45 & 0.48 & 0.52 & 0.51 & 16 \\
\hline 7 & 58 & -0.24 & -0.01 & -0.14 & 11 \\
\hline 8 & -54 & 0.47 & 0.51 & 0.35 & 9 \\
\hline 9 & -20 & 0.88 & 0.90 & 0.90 & 10 \\
\hline 10 & -16 & 0.90 & 0.90 & 0.88 & 9 \\
\hline 11 & -3 & 0.97 & 0.96 & 0.93 & 7 \\
\hline 12 & -42 & 0.61 & 0.66 & 0.66 & 15 \\
\hline 13 & -35 & 0.67 & 0.71 & 0.70 & 16 \\
\hline 14 & 116 & -2.37 & -1.94 & -3.43 & 2 \\
\hline 15 & -30 & 0.76 & 0.81 & 0.86 & 12 \\
\hline 16 & -19 & 0.84 & 0.79 & 0.91 & 13 \\
\hline 17 & - & - & - & - & - \\
\hline 18 & -5 & 0.87 & 0.78 & 0.86 & 17 \\
\hline
\end{tabular}

\subsection{Distribution of $\mathrm{SSY}_{\mathrm{a}}$ Using Regionalized $\mathrm{USG}_{\mathrm{a}}$}

Exclusively for regionalization purpose, CAT-17 was taken into account because it can introduce a diversity that could be advantageous for ungauged catchment modeling (Oudin et al., 2008). In this section, the predicted $\mathrm{SSY}_{\mathrm{a}}$ in each modeled catchment was distributed monthly based upon $\mathrm{USG}_{\mathrm{a}}$ regionalized using the spatial proximity approach. As a result shown in Table 3 , the predictive accuracy measured by NSE ranges between -3.43 and 0.93 (median $=0.66)$. There are also 11 modeled catchments having NSE value greater than 0.50 . In comparing with the double-average $\mathrm{USG}_{\mathrm{a}}$, the uncertainty was increased although the median NSE value of both approaches is approximately the same. 
Moreover, the regionalized $\mathrm{USG}_{\mathrm{a}}$ technique performs worse (less NSE) in 10 out of 17 catchments. In these 10 catchments (No. 2 and 6-14), the prediction was deteriorated overall for peak value (in September). It is vice versa in other seven catchments. Figure 6 shows an example of time series comparison in CAT11 and CAT-16. Shortly, the regionalized $\mathrm{USG}_{\mathrm{a}}$ is inferior to the double-average $\mathrm{USG}_{\mathrm{a}}$.

\section{CONCLUSION}

In the LMB, huge amount of hydropower, irrigation and other water-related projects requiring the information of sediment for the design and management have been planned in the basin part of Lao PDR, Cambodia and Vietnam where sediment data are poorly gauged or ungauged. Therefore, this study is to develop a regional SSY model for use in ungauged areas. Firstly, accuracy of the traditional method for $\mathrm{SSY}_{\mathrm{a}}$ prediction was advanced by substituting $\mathrm{A}_{0}$ (the predictor) with $\mathrm{A}_{15}$ and the overall predictive accuracy in term of MAPE was improved about $66 \%$. Then the predicted $\mathrm{SSY}_{\mathrm{a}}$ in each modeled catchment was distributed monthly by mean of $\mathrm{USG}_{\mathrm{a}}$. The double-average $\mathrm{USG}_{\mathrm{a}}$ superior to the singleaverage one offers overall better quality results than the regionalized $\mathrm{USG}_{\mathrm{a}}$ dependent upon the spatial proximity approach. The inferiority of the regionalized $\mathrm{USG}_{\mathrm{a}}$ could be attributed to the sparse network of catchments used in the study.

As a whole from statistically comparing the model results with the corresponding observed data in each study catchment, $\mathrm{SSY}_{\mathrm{a}}$ and $\mathrm{SSY}_{\mathrm{m}}$ in ungauged areas could be measured with an accuracy of $44 \%$ in term of MAPE and 0.66 in term of median NSE, respectively. Last but not least, the proposed approach could be potentially and feasibly employed to provide solutions to sediment-ungauged issues in the basin. This research is also an important work to be referred in land management and planning.

\section{ACKNOWLEDGEMENT}

The authors are sincerely grateful to Japanese Government (Monbukagakusyo: MEXT) and GCOE program of University of Yamanashi for financially supporting this research study. Many thanks are also extended to Mekong River Commission for providing datasets.

\section{REFERENCES}

Bao, Z., J. Zhang, J. Liu, G. Fu and G. Wang et al., 2012. Comparison of regionalization approaches based on regression and similarity for predictions in ungauged catchments under multiple hydro-climatic conditions. J. Hydrol., 466-467: 37-46. DOI: 10.1016/j.jhydrol.2012.07.048

Cibin, R., P. Athira, K.P. Sudheer and I. Chaubey, 2013. Application of distributed hydrological models for predictions in ungauged basins: A method to quantify predictive uncertainty. Hydrol. Proces. DOI: 10.1002/hyp.9721

Francke, T., J.A. Lopez-Tarazon and B. Schroder, 2008. Estimation of suspended sediment concentration and yield using linear models, random forests and quantile regression forests. Hydrol. Proces., 22: 4892-4904. DOI: 10.1002/hyp.7110

Fuchs, H.J., 2004. Data availability for studies on effects of land-cover changes on water yield, sediment and nutrient load at catchments of the lower Mekong basin. MRC-GTZ Cooperation Programme, Göttingen, Germany.

Heng, S. and T. Suetsugi, 2013. Estimating quantiles of annual maximum suspended sediment load in the tributaries of the Lower Mekong River. J. Water Climate Change, 4: 63-76. DOI: 10.2166/wcc.2013.023

Isik, S., 2013. Regional rating curve models of suspended sediment transport for Turkey. Earth Sci. Inform., 6: 87-98. DOI: 10.1007/s12145-013-0113-7

Kummu, M., X.X. Lu, J.J. Wang and O. Varis, 2010. Basin-wide sediment trapping efficiency of emerging reservoirs along the Mekong. Geomorphology, 119: 181-197. DOI: 10.1016/j.geomorph.2010.03.018

Melesse, A.M., S. Ahmad, M.E. McClain, X. Wang and Y.H. Lim, 2011. Suspended sediment load prediction of river systems: An artificial neural network approach. Agric. Water Manage., 98: 855866. DOI: 10.1016/j.agwat.2010.12.012

Moriasi, D.N., J.G. Arnold, M.W.V. Liew, R.L. Bingner and R.D. Harmel et al., 2007. Model evaluation guidelines for systematic quantification of accuracy in watershed simulations. Trans. Am. Soc. Agric. Biol. Eng., 50: 885-900.

Morris, G.L. and J. Fan, 1998. Reservoir Sedimentation Handbook. Electronic Version 1.04. 1st Edn., McGraw-Hill, New York, ISBN-10: 007043302X, pp: 805. 
MRC, 2009. Lower Mekong hydropower database. MRC, Vientiane, Lao PDR.

MRC, 2011. Planning atlas of the lower Mekong river basin. MRC, Phnom Penh, Cambodia and Vientiane, Lao PDR.

Oudin, L., V. Andréassian, C. Perrin, C. Michel and N.L. Moine, 2008. Spatial proximity, physical similarity, regression and ungaged catchments: A comparison of regionalization approaches based on 913 French catchments. Water Resour. Res., 44: W03413W03413. DOI: 10.1029/2007WR006240

Seibert, J. and J. McDonnell, 2013. Gauging the ungauged basin: The relative value of soft and hard data. J. Hydrol. Eng. DOI: 10.1061/(ASCE)HE.1943-5584.0000861

Tamene, L., S.J. Park, R. Dikau and P.L. Vlek, 2006. Reservoir siltation in the semi-arid highlands of northern Ethiopia: Sediment yield-catchment area relationship and a semi-quantitative approach for predicting sediment yield. Earth Surface Process Landforms, 31: 1364-1383. DOI: 10.1002/esp.1338

Verstraeten, G., J. Poesen, J.D. Vente and X. Koninckx, 2002. Sediment yield variability in Spain: A quantitative and semiqualitative analysis using reservoir sedimentation rates. Geomorphology, 50: 327-348. DOI: 10.1016/S0169-555X(02)00220-9

Walling, D.E. and D. Fang, 2003. Recent trends in the suspended sediment loads of the world's rivers. Global Planetary Change, 39: 111-126. DOI: 10.1016/S0921-8181(03)00020-1
Walling, D.E., 2005. Evaluation and analysis of sediment data from the lower Mekong river. Mekong River Commission, Vientiane, Lao PDR.

Wang, H., Z. Yang, Y. Wang, Y. Saito and J.P. Liu, 2007. Reconstruction of sediment flux from the Changjiang (Yangtze River) to the sea since the 1860s. J. Hydrol., 349: 318-332. DOI: 10.1016/j.jhydrol.2007.11.005

Wang, J.J., X.X. Lu and M. Kummu, 2009. Sediment load estimates and variations in the Lower Mekong River. River Res. Applic., 27: 33-46. DOI: 10.1002/rra.1337

Zhang, W., X. Wei, J. Zheng, Y. Zhu and Y. Zhang, 2012. Estimating suspended sediment loads in the Pearl River delta region using sediment rating curves. Continental Shelf Res., 38: 35-46. DOI: 10.1016/j.csr.2012.02.017

Zhang, Y. and F.H.S. Chiew, 2009. Relative merits of different methods for runoff predictions in ungauged catchments. Water Resour. Res., 45: W07412W07412. DOI: 10.1029/2008WR007504

Zhao, F., F.H.S. Chiew, L. Zhang, J. Vaze and J.M. Perraud et al., 2012. Application of a macroscale hydrologic model to estimate stream flow across Southeast Australia. J. Hydrometeorol., 13: 12331250. DOI: 10.1175/JHM-D-11-0114.1 